\title{
Investigation of Spatial and Temporal Distribution of Snow Cover by Using Satellite Imagery (Case Study: Sheshpirdam Basin)
}

\author{
Ali Liaghat ${ }^{* \#, ~ N i m a ~ T a v a n p o u r ~}{ }^{2 \#}$ \\ ${ }^{1}$ Department of Water Engineering Shiraz Branch, Islamic Azad University, Shiraz, Iran \\ ${ }^{2}$ Department of Water Engineering, Faculty of Agriculture, Shiraz University, Shiraz, Iran \\ Email: *ali.liaghat010@chmail.ir
}

Received 29 March 2016; accepted 27 May 2016; published 30 May 2016

Copyright (C) 2016 by authors and Scientific Research Publishing Inc.

This work is licensed under the Creative Commons Attribution International License (CC BY).

http://creativecommons.org/licenses/by/4.0/

(c) (i) Open Access

\begin{abstract}
About one third of the water needed for agriculture in the world is generated by melting snow. Snow cover, surface and ground water recharge are considered as sustainable and renewable resources. It is therefore necessary to identify and study these criteria. The aim of this study is to determine the spatial and temporal distribution of snow cover in the district of the Sheshpir basin in Fars province (in south of Iran). Ground-based observation of snow covers, especially in mountainous areas, is associated with many problems due to the insufficient accuracy of optical observation, as opposed to digital observation. Therefore, GIS and remote sensing technology can be partially effective in solving this problem. Images of Landsat $5^{\mathrm{TM}}$ and Landsat $7^{\mathrm{TM}}$ satellites were used to derive snow cover maps. The images in ENVI 4.8 software were classified by using the maximum likelihood algorithm. Other spatial analyses were performed in ARC-GIS 9.3 software. The maximum likelihood method was accuracy assessed by operation points of testing. The least and the average of overall accuracy of produced maps were found to be $91 \%$ and $98 \%$, respectively. This demonstrates that the maximum likelihood method has high performance in the classification of images. Overall snow cover and the review of terrain through the years 2008-2009 and 2009-2010 showed that snow cover begins to accumulate in November and reaches its highest magnitude in February. Finally, no trace of snow can be observed on the surface of the basin in the month of May. By average, 34\% of the basin is covered in snow from November through to May.
\end{abstract}

\footnotetext{
"Corresponding author.

${ }^{\#}$ Ali Liaghat—Instructor (Ph.D. student); Nima Tavanpour—Ph.D. Student of Water Engineering
} 


\section{Keywords}

\section{RS, GIS, Maximum Likelihood Algorithm, Snow Cover, Spatial and Temporal Distribution}

\section{Introduction}

The importance and valuable position of water is common knowledge to the modernity of human life and the current population on Earth. Industrial and municipal lifestyles have multiplied the overall consumption of water to an extent that is incomparable to the traditional lifestyle of mankind. Nowadays, the management of water resources is presented as one of the most decisive parameters in social and political planning, especially in countries with arid and semi-arid climates where the optimization of water resources and consumption are essential. A small fraction of the Earth's land area is mountainous, where the majority of surface-water and groundwater recharge emanates from snow-covered hilltops and results from the melting of ice. More than $40 \%$ of the northern hemisphere is covered with snow in winter, and this accounts to 30\% of the Earth's total land area, while only $10 \%$ of the Earth's land area is covered with snow and ice throughout the year. According to current estimates on the global scale, nearly one-third of the required water for agriculture in the world is obtained by the melting of seasonal snow, and this melting provides drinking water for 1 billion people on the planet [1]. Snow is a stable and sustainable source for the maintenance of surface-water and underground water basins. In some regions of the western United States, surface-water caused by the melting of ice can almost meet the entire water demand for the industry, agronomy and sanitation purposes. In Norway, 99\% of the electrical power production is of hydroelectricity [2]. Since this paper examines the snow-cover of a river basin in Iran, it is worthwhile to note that $78 \%$ of rain in Iran falls on mountainous terrain [3]. According to previous evaluations, approximately $60 \%$ of surface-water and $57 \%$ of groundwater in Iran are located near snow-covered zones and are sustained by the melting of ice [4]. Snow is the main determinant parameter engaged in the hydrological cycle in mountainous basins. The melting of snow comprises the major component of river streams in these basins [5]. Tekeli et al. examined the applicability of snow cover maps-derived from Moderate Resolution Imaging Spectroradiometer (MODIS) data-in the simulation of runoff that resulted from the melting of snow in eastern Turkey. In the first step, the diurnal snow cover maps were extracted from MODIS images and via the assistance of Normalized Difference Snow Index (NDSI). Then, these maps were compared with data obtained from field measurements pertaining to the years 2002-2003 and 2003-2004 [6]. Lopez et al. (2008) monitored the snow cover of the Northern Patagonia Ice field (NPI) after applying the Normalized Difference Snow Index (NDSI) and Red/NIR band ratio to 134 Moderate Resolution Imaging Spectro-radiometer (MODIS) images captured between 2000 and 2006. The final results showed that the snow cover extent of the NPI fluctuates a lot in winter, in addition to its seasonal behaviour. The minimum snow cover extent of the period $\left(3600 \mathrm{~km}^{2}\right) \mathrm{was}^{2}$ observed in March 2000 and the maximum (11,623 km²) in August 2001 [7]. They found that temperature accounts for approximately $76 \%$ of the variation of the snow cover extent over the entire ice field. Immerzeel et al. (2009) used various remote sensing products to identify spatial-temporal trends in snow cover in river basins originating in the Himalayas and adjacent Tibetan-Qinghai plateau. It was shown that remote sensing allows detection of spatial-temporal patterns of snow [8]. Results showed large variation in snow cover between years while an increasing trend from west to east was observed. Of all river basins the Indus basin is, for its water resources, most dependent on snow and ice melt and large parts are snow covered for prolonged periods of the year. A significant negative winter snow cover trend was identified for the upper Indus basin. Harshburger et al. (2010) applied the heat temperature index to estimate the amount of snow stored in the mountains, and used maximum and minimum critical temperatures to differentiate between solid precipitation (snow), liquid precipitation (rain) and the combination of both. Such measures were taken to optimize the function of the SRM and assist in its proper application. By comparison, this simulation showed a substantial improvement in the function of the model [9]. Wang et al. (2015) examined snow cover dynamics and their response to climate change using new, daily cloud-free snow-cover products. The results demonstrated that the daily cloud-free snow-cover products not only posses the advantages of the AMSR-E (unaffected by weather conditions) and MODIS (relatively higher resolution) products, but are also characterized by high snow and overall classification accuracies 
( $\sim 85 \%$ and $\sim 98 \%$, respectively), substantially greater than those of the existing daily snow-cover products for all sky conditions and very similar to, or even slightly greater than, those of the daily MODIS products for clear-sky conditions. Using the snow-cover products, we analyzed the snow cover dynamics over the Tibetan Plateau and determined that the maximum number of snow covered days (SCD) in a year followed a decreasing tendency from 2003 to 2010, with a decrease in snow-covered area (SCA) equivalent to $55.3 \%$ of the total Tibetan Plateau area.

Surface-water that result from the melting of ice or rainfall can play a substantial role in the administration of water resources via proper management of agricultural projects, flood alerting systems and the exploitation of water reservoirs of dams. In some mountainous terrain, precipitation occurs mainly in the form of snow which is an important source for the ensuing runoff. The characteristics of snow are such that cause a variety of ecological and hydrological differences in their area of precipitation, which is comparable to rainfall. These variations can be the cause of important effects in the natural environment. The understanding of these effects and their mechanisms can assist environmentalist managers to optimize the exploitation of environmental potentials. Therefore, it is highly useful to gain information of the area where snow subsists in a mountainous region, through the months of the year, besides knowing the mechanism of snow melting and the resultant runoff. The aim of the current study is to evaluate the temporal and spatial distribution of snow in the area of Sheshpir basin.

\section{Materials and Methods}

\subsection{Studied Area}

The Sheshpir river basin is situated in the southwestern domain of the Zagros Mountains, northwest of the Fars province (in south of Iran) (Figure 1).

This river emanates from the high altitudes of the Gar Mountain, where it is initially called Cal Gamil by the locals. The river continues through to the Salaki village where it is then accordingly called Salaki. And after passing the districts of the Sheshpir village, it acquires its ultimate name, Sheshpir. The outlet of the basin is located close to the Gashnegan village, east of the Sepidan municipality. Sepidan is about $100 \mathrm{~km}$ away from Shiraz, the center of Fars province. The region under study has an area of $55.95 \mathrm{~km}^{2}$ when considering the source and the outlet as its two ends. It is located between the geographic longitudes of 592935 and 606105, while its latitudes are between 3341505 and 3358125, as determined by the UTM-WGS 1984 coordination system. The minimum elevation of the basin is $2260 \mathrm{~m}$ and the maximum is $3694 \mathrm{~m}$ above sea level. The rainfall pattern in the region is mainly centered in winter. Nearly $60 \%$ of the annual precipitation occurs in winter. Autumn and

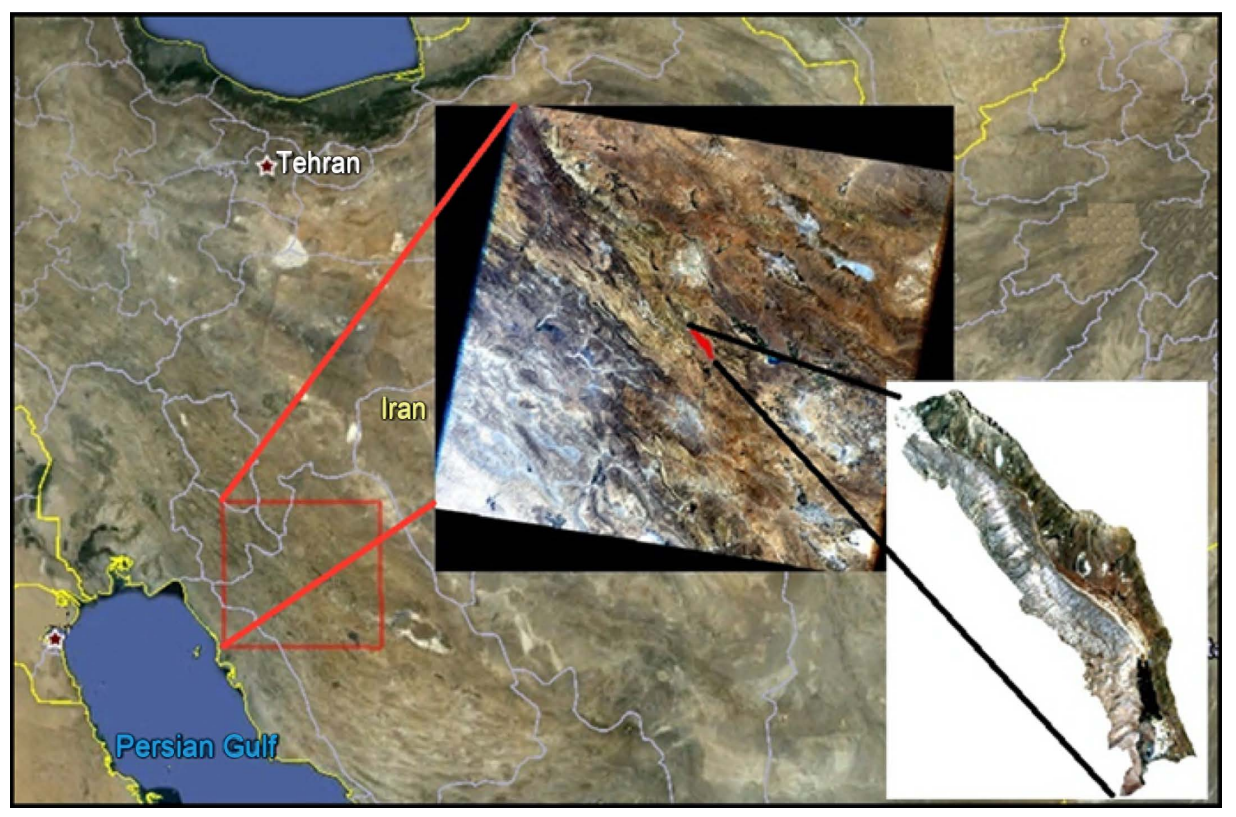

Figure 1. Studied area situation. 
spring are second and third in hosting the highest amount of precipitation. The average amount of precipitation in the basin is $912.9 \mathrm{~mm}$ while the average temperature on the area of the basin is $10^{\circ} \mathrm{C}$. The basin's climate is classified as very moist and humid based on Dumarten's classification, while based on the Amberje method it is classified as in the region of high-altitude climates [10].

\subsection{Analysis of Satellite Images}

Methods of remote sensing are commonly applied along with local information systems and satellite information so as to reconstruct, exhibit and simulate certain aspects of the natural environment that cannot be experimented or simulated otherwise, or would consume unaffordable amounts of time and finance. In this research, the use and analysis of satellite images are central to the evaluation of temporal and spatial distribution of snow-cover in the mountainous region of Sheshpir river basin.

\subsection{Available Data for Analysis}

The images used for this study were readily obtained by the Thematic Mapper (TM) and the Enhanced Thematic Mapper (ETM) which are positioned on LandSat 5 and LandSat 7 satellites. The images corresponded to the path $=163$ and row $=39$ of the satellite. A total number of 22 dates was considered on the rainfall calendar to extract the area of snow-cover for the years 2008-2009 and 2009-2010. The obtained images are the most of what was available as usable images for research. Details of the images are presented in Table 1. Furthermore, digital maps of topography $(1: 25,000)$ have been used, which had been made available by the institute of national topography in Iran.

The LandSat is a renowned satellite that has been launched into the Earth's orbit by NASA. It covers a band of land mass measuring $185 \mathrm{~km}$ in width as it moves in its orbit. The complete coverage of the Earth's surface takes 16 days to obtain in the form of images. The mappers deployed on LandSat have good image resolution as regards radiometric and spatial parameters. The Enhanced Thematic Mapper (ETM) has special potentials in comparison with the LandSat 4 and 5 mappers (TM). The ETM has the better spatial resolution of thermal band which is 60 meters, while the same value is 120 meters in the case of TM. The panchromatic band and relevant regulators optimize the transformation and regulation of radiometric energy pertaining to the mapper's data. Table 2 presents details of the TM and ETM.

\subsection{Pre-Analysis of Satellite Images}

Data and images need to be prepared for analysis and the extraction of necessary information. The first step in the preparation of data is the radiometric correction of images. The radiometric correction is primarily concerned

Table 1. Properties of produced images properties.

\begin{tabular}{cccc}
\hline Date & Satellite & Date & Satellite \\
\hline $10 / 16 / 2009$ & LandSat 5 & $10 / 21 / 2008$ & LandSat 7 \\
$11 / 1 / 2009$ & LandSat 5 & $12 / 24 / 2008$ & LandSat 7 \\
$11 / 17 / 2009$ & LandSat 5 & $1 / 9 / 2009$ & LandSat 7 \\
$12 / 3 / 2009$ & LandSat 5 & $1 / 17 / 2009$ & LandSat 5 \\
$1 / 20 / 2010$ & LandSat 5 & $2 / 2 / 2009$ & LandSat 5 \\
$2 / 5 / 2010$ & LandSat 5 & $2 / 26 / 2009$ & LandSat 7 \\
$4 / 10 / 2010$ & LandSat 5 & $3 / 6 / 2009$ & LandSat 5 \\
$4 / 26 / 2010$ & LandSat 5 & $4 / 7 / 2009$ & LandSat 5 \\
$5 / 28 / 2010$ & LandSat 5 & $5 / 25 / 2009$ & LandSat 5 \\
$6 / 5 / 2010$ & LandSat 7 & $6 / 10 / 2009$ & LandSat 5 \\
$7 / 15 / 2010$ & LandSat 5 & $6 / 26 / 2009$ & LandSat 5 \\
\hline
\end{tabular}


Table 2. Properties of LansSat 5 and LandSat 7 satellites.

\begin{tabular}{|c|c|c|c|c|c|}
\hline Spatial resolution $(\mathrm{m})$ & Spectral range name & Spectral range of band (micrometer) & Band number & Sensor & Satellite \\
\hline 20 & Blue & $0.45-0.52$ & 1 & \multirow{7}{*}{ 家 } & \multirow{7}{*}{ 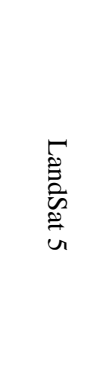 } \\
\hline 30 & Green & $0.52-0.6$ & 2 & & \\
\hline 30 & Red & $0.63-0.69$ & 3 & & \\
\hline 30 & Near infrared & $0.76-0.9$ & 4 & & \\
\hline 30 & Middle-infrared & $1.55-1.75$ & 5 & & \\
\hline 120 & Thermal infrared & $10.4-12.5$ & 6 & & \\
\hline 30 & Middle infrared & $2.08-2.35$ & 7 & & \\
\hline 30 & Blue & $0.45-0.515$ & 1 & \multirow{8}{*}{ 莺 } & \multirow{8}{*}{$\begin{array}{l}\stackrel{ }{0} \\
\stackrel{0}{0} \\
\stackrel{0}{\sim}\end{array}$} \\
\hline 30 & Green & $0.525-0.605$ & 2 & & \\
\hline 30 & Red & $0.63-0.69$ & 3 & & \\
\hline 30 & Near infrared & $0.75-0.9$ & 4 & & \\
\hline 30 & Middle-infrared & $1.55-1.75$ & 5 & & \\
\hline 60 & Thermal infrared & $10.4-12.5$ & 6 & & \\
\hline 30 & Middle-infrared & $2.09-2.35$ & 7 & & \\
\hline 15 & - & $0.52-0.9$ & Panchromatic & & \\
\hline
\end{tabular}

with errors made by the mapper and errors that arise as a result of the atmosphere. In this research, however, the images are free from errors by the mapper. The second step is the geometric correction of the images. This correction is applied to compensate for any possible deviations that might have occurred. For this purpose, seventeen control points were selected on land, including the intersection of minor roads and major roads, squares and road twists.

The geographic coordination of these control points were recorded in the region via a GPS.

Collected data were located on False Color Composite images 3-2-1 (FCC) in the ENVI 4.8 software via the metric system. In this research, geometric corrections were performed by polynomial equations of quadratic formulae and by 15 control points with the capability of being located on the FCC. Normally, the acceptable RMSE is less than 1 and should be preferably less than 0.5 in value. In this method and in this case, the sum added up to 0.21 in total.

Collected data were located on False Color Composite images 3-2-1 (FCC) in the ENVI 4.8 software via the metric system. In this research, geometric corrections were performed by polynomial equations of quadratic formulae and by 15 control points with the capability of being located on the FCC. Normally, the acceptable RMSE is less than 1 and should be preferably less than 0.5 in value. In this method and in this case, the sum added up to 0.21 in total.

\subsection{Unsupervised Classification}

The clustering of similar spectral groups and classifying those with similar spectral response patterns is the classification of satellite information. In other words, the classification of pixels that comprise an image, the attribution or introduction of each pixel to a particular class or phenomenon can be termed as the classification of satellite information. Classification can be done in two forms: optical and digital. Digital classification is based on variations in the spectral behavior of different physical features on different spectral bands. However, this should not imply that each feature is a separable entity on a particular band. The optical classification is an inferior method in that the human eye is incapable of recognizing the many differences in the image which would have been separable if the digital method was applied. Digital data and remote sensing with a high degree of resolution offer a better opportunity for the classification and analysis of features in an image, compared to the 
method of optical analysis. In the digital method, a selection of pixels is chosen as samples and their properties are provided via relevant software for computer analysis [11]. Operation points of testing are chosen as samples in a way that each represents the properties of a particular cluster (class) exclusively [12].

\subsection{Maximum Likelihood Method}

Among the methods for supervised classification, the maximum likelihood is considered as the most precise and prevalent method. It evaluates the variance and covariance of classes and clusters. This method supposes that the operation points of testing have normal distribution. Samples in classes for the points of testing should be authentic representatives of their class. Therefore, it is best to use a large number of samples so that the frequent variances in the spectral pattern appear as a continuous domain. The normal distribution is an essential pre- requisite for the enactment of this method [11].

\subsection{Classified Analysis}

The worth and potential applicability of any produced map depends on its accuracy. A common way for assessing the accuracy of maps, which result from classification, is to use details and information relating to the terrain or operation points of testing. These points (regions) include samples taken arbitrarily from the classes (clusters) under study. A definition of error would be the difference between the reality and what the observer reports as the reality. The matrix of error can evaluate the correctness and preciseness of map classifications. In order to evaluate the correctness of classification results, accuracy parameters can be assessed by the error matrix for maps that are produced by classification of pixels.

\section{Results and Discussion}

Classification was performed by the maximum likelihood method and the composite band 5-4-1, whereby the operation points of testing were established for the image class of snow-cover per calendar date. Images were categorized into two classes of snow-cover and none-snow-cover. Then, the classified images were shuffled by the GIS software with regard to the territory of the basin. Information was extracted regarding the pixels showing the snow cover and pixels showing none-snow-cover areas, leading to the refined display of final images showing clear-cut areas. Results pertaining to classification are shown in Table 3.

Following classification, the errors and accuracy of produced maps were evaluated to assess the overall classification by designating experimental points in the snow-covered area. This was performed via a confusion

Table 3. Characteristics of snow cover in Sheshpir basin.

\begin{tabular}{cccc}
\hline Date & Snow cover area $\left(\mathbf{K m}^{2}\right)$ & Lack of snow cover area $\left.\mathbf{( K m}^{2}\right)$ & Snow cover $($ percent) \\
\hline $12 / 24 / 2008$ & 12.44 & 43.51 & 22.24 \\
$1 / 9 / 2009$ & 35.45 & 20.49 & 63.37 \\
$1 / 17 / 2009$ & 29.84 & 26.11 & 53.33 \\
$2 / 2 / 2009$ & 53.97 & 2.16 & 96.14 \\
$2 / 26 / 2009$ & 11.18 & 44.77 & 19.98 \\
$3 / 6 / 2009$ & 9.23 & 46.72 & 16.5 \\
$4 / 7 / 2009$ & 9.61 & 46.34 & 17.18 \\
$12 / 3 / 2009$ & 20.91 & 35.04 & 37.38 \\
$1 / 20 / 2010$ & 14.96 & 40.99 & 26.74 \\
$2 / 5 / 2010$ & 39.85 & 16.09 & 71.23 \\
$4 / 10 / 2010$ & 2.01 & 53.93 & 3.6 \\
$4 / 26 / 2010$ & 0.47 & 55.48 & 0.83 \\
\hline
\end{tabular}


matrix. Figure 2 shows the operation points of testing and the experimental points in December 3, 2009.

The accuracy of produced maps is described in Table 4.

The maximum likelihood algorithm was used for the classification and production of snow cover maps. This method is known to perform efficiently for the classification of snow cover. The reason for efficient performance is because all of the maps produced by this method and in this research are of high accuracy. The lowest overall accuracy of the produced maps was $91.3 \%$ and the average of overall accuracy for the produced maps was $97.84 \%$, which proves the high efficiency of the maximum likelihood method in the classification of images. The snow cover maps produced in this research are presented in Figure 3.

\section{Conclusion}

This study on the snow cover of the Sheshpir river basin during the years 2008-2009 and 2009-2010 showed that the accumulation of snow in this basin begins in November and reaches a peak in February. Thereafter the trend is reduced and reaches a minimum rate of snow accumulation by the beginning of spring. Finally, the snow undergoes gradual melting until no snow can be found in any part of the basin in May. On average, $34 \%$ of the
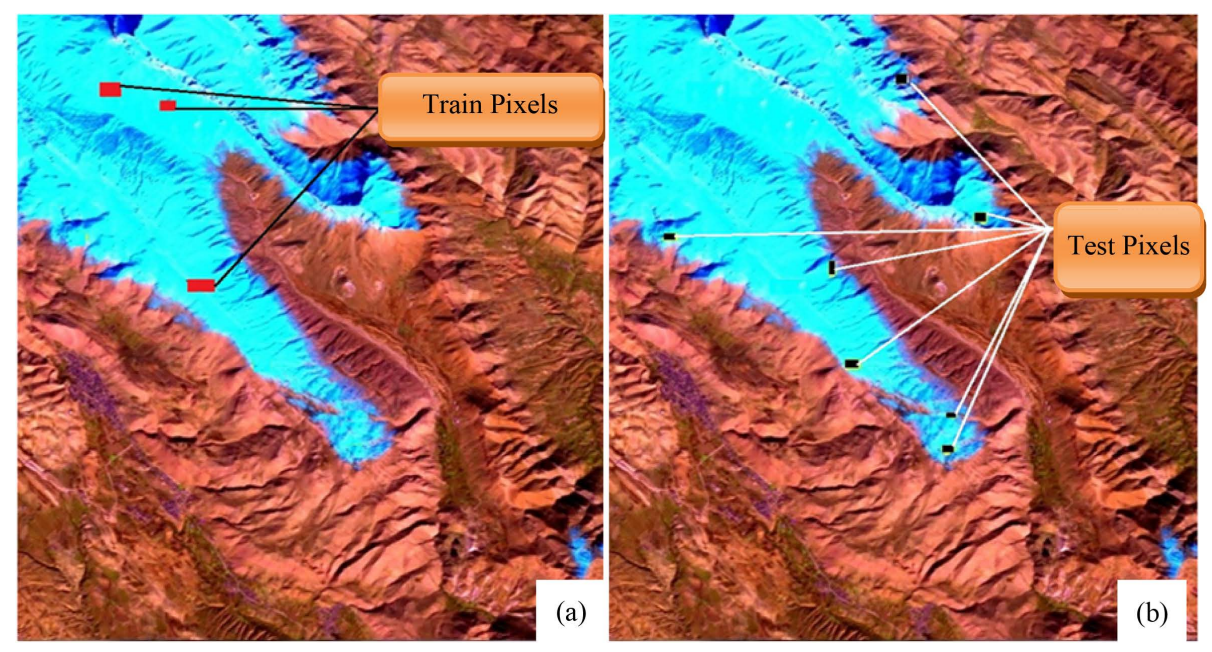

Figure 2. (a) Train pixels and (b) test pixels.

Table 4. Accuracy of produced maps in different dates.

\begin{tabular}{ccc}
\hline Date & Total accuracy (percent) \\
\hline $12 / 24 / 2008$ & 97.1939 \\
$1 / 9 / 2009$ & 98.9080 \\
$1 / 17 / 2009$ & 96.4361 \\
$2 / 2 / 2009$ & 100 \\
$2 / 26 / 2009$ & 97.6 \\
$3 / 6 / 2009$ & 99.5098 \\
$4 / 7 / 2009$ & 91.3043 \\
$12 / 3 / 2009$ & 100 \\
$1 / 20 / 2010$ & 99.0741 \\
$2 / 5 / 2010$ & 98.8909 \\
$4 / 10 / 2010$ & 99.5690 \\
$4 / 26 / 2010$ & 96.6102 \\
\hline
\end{tabular}




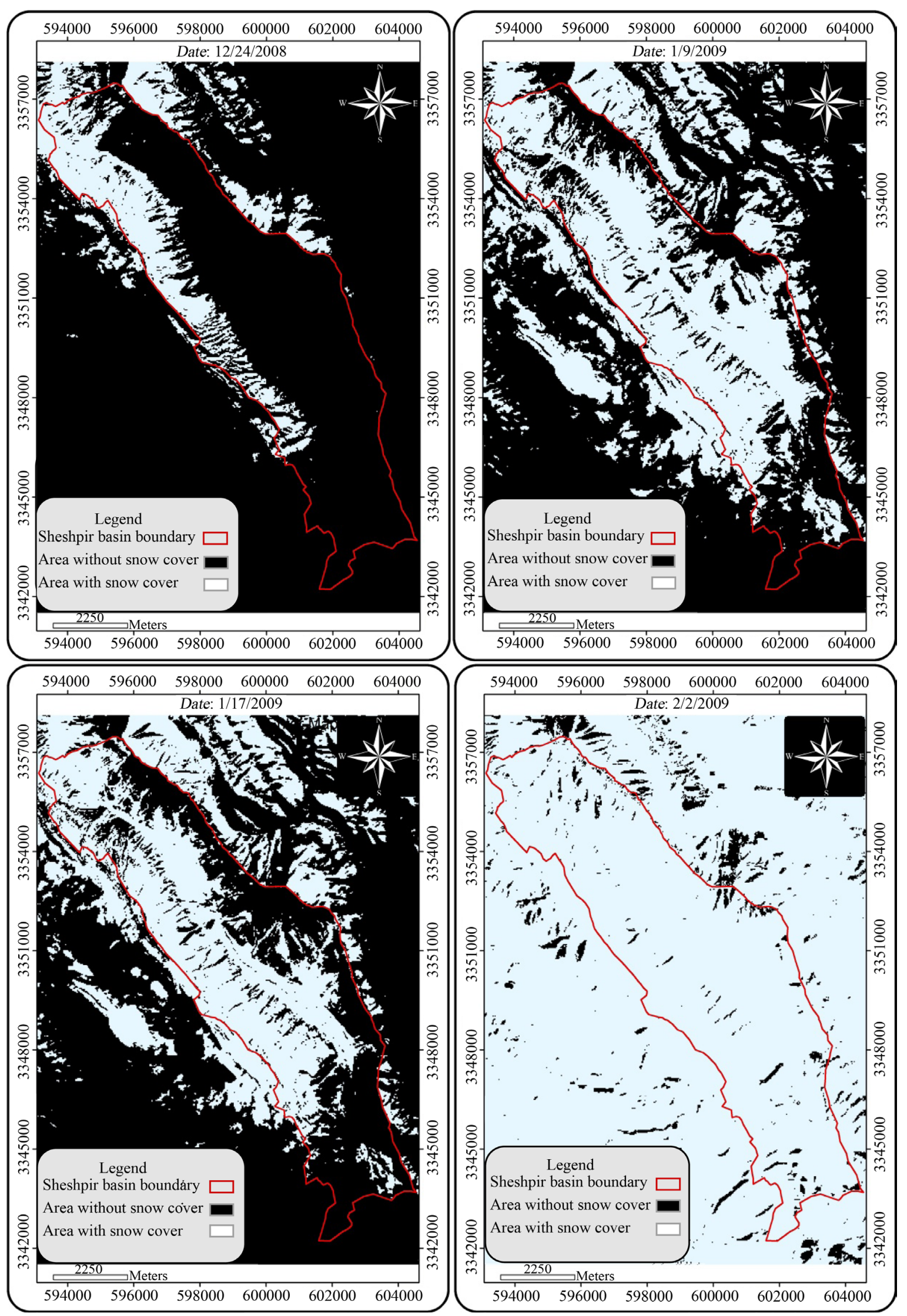



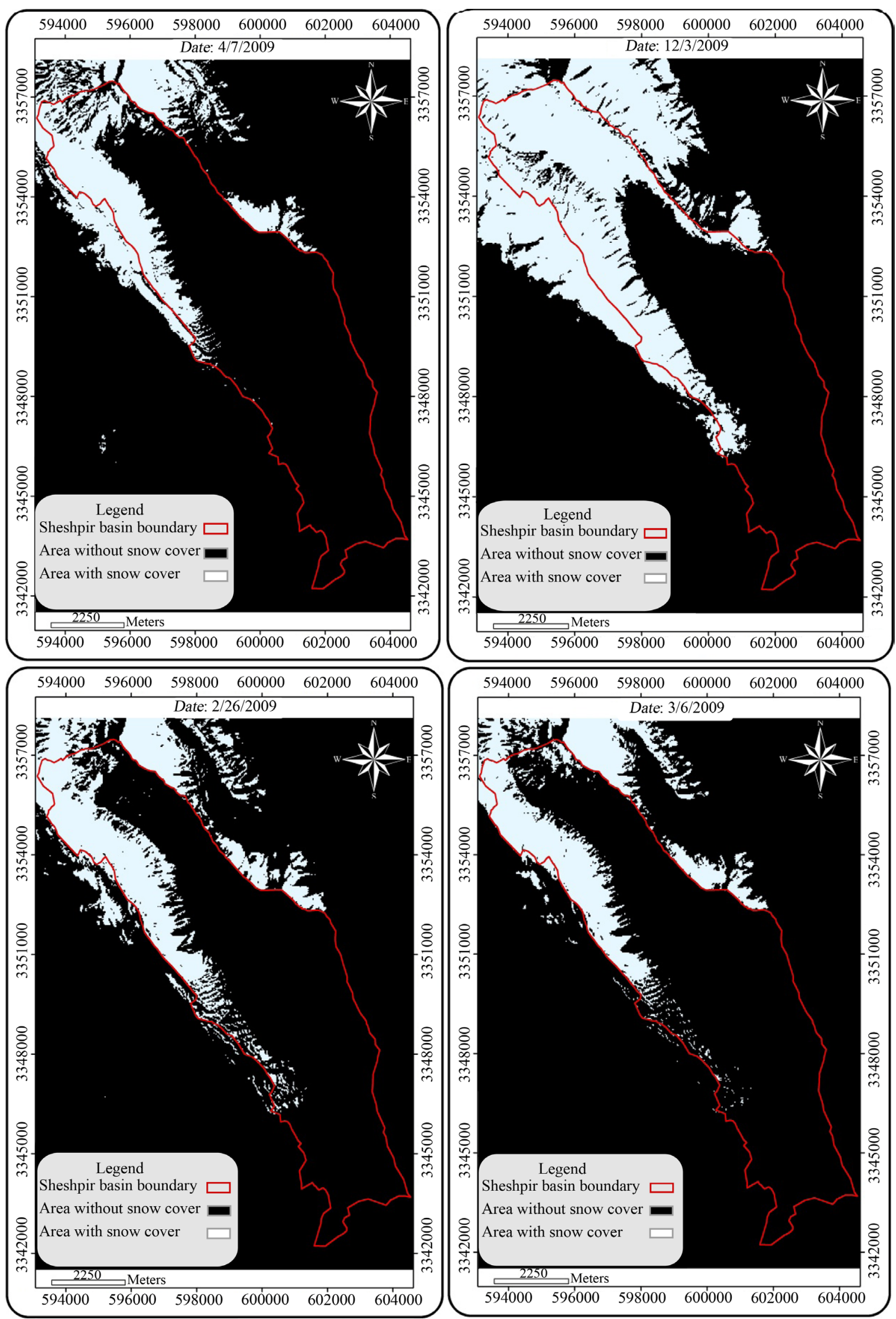

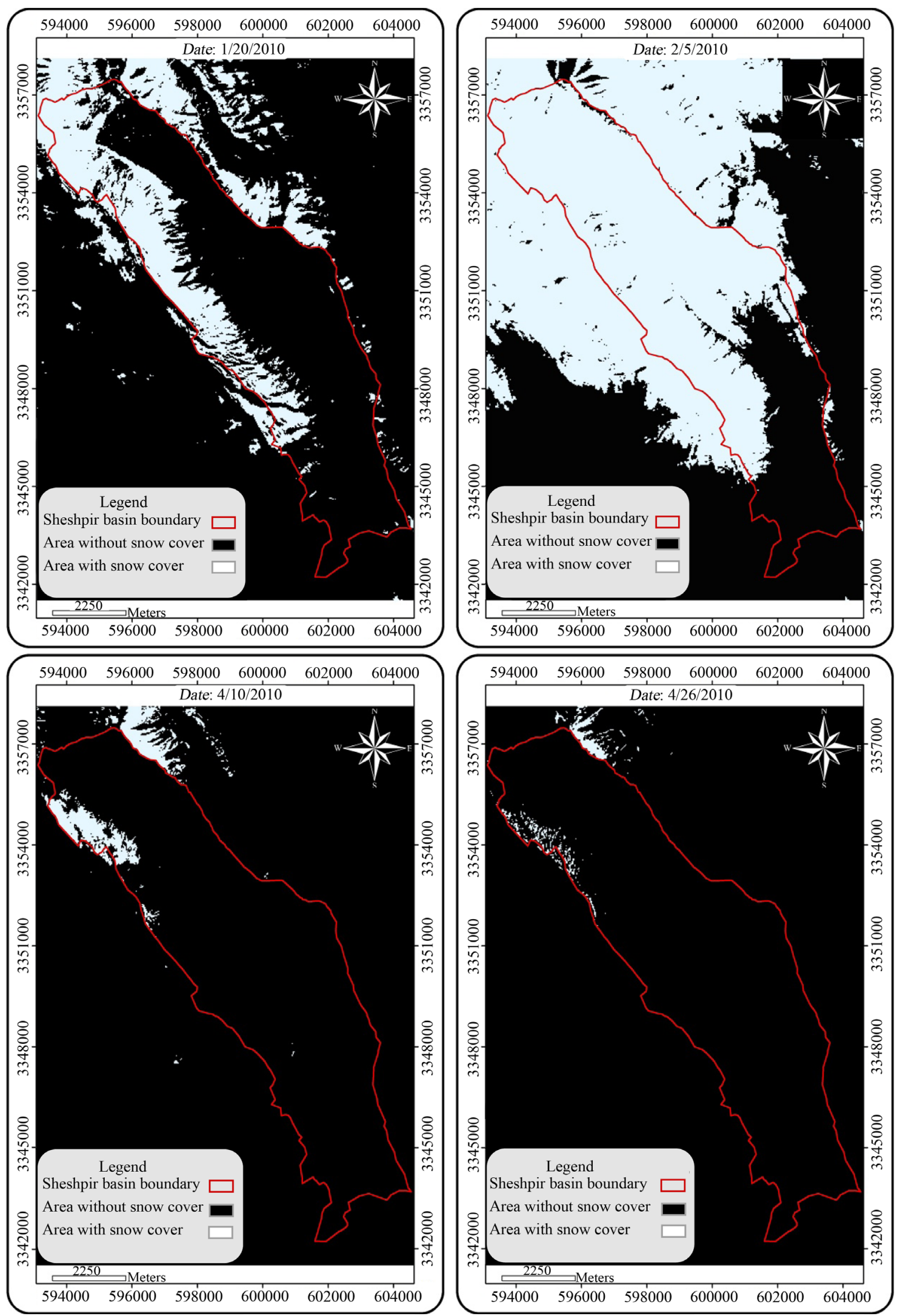

Figure 3. Maps of snow cover in Sheshpir basin. 
region's area is covered in snow from November to May.

\section{References}

[1] Raigani, B., Khajeddin, S.J., Soltani Koopaie, S. and Barati, S. (2008) Calculating Changes in Snow-Cover Maps Obtained from MODIS Satellite Images at Times When No Other Image Was Available. Science and Research Periodical of Water and Soil (Science and Expertise of Agriculture and Natural Resources), 44, 315-331.

[2] Taheri-Shahr Ayini, H., Tajrishi, M., Jalali, N. and Abrishamchi, A. (2002) Extracting the Practical Model for the Relation Between the Area of Hamoon Waters and the Area of Snow Cover in the Hirmand Dam Basin Performed by Satellite Images. Collection of Articles Presented in the Third Conference on Hydraulics in Iran, Engineering University of Tehran, Tehran, 437-444.

[3] Alizadeh, A. (2010) Fundamentals of Applied Hydrology. 27th Edition, Imam Reza University Press, Mashhad.

[4] Seyyedi Alam Abadi, M., Moradi, H.R. and Ghanbarpour, M.R. (2009) Estimating the Runoff Resulting from Snowmelt via IRS Satellite Images and the Application of Statistical Models for a Case Study: Zarrineh Rood Watershed Basin. Science and Research Periodical of Iranian Watershed Management, 9, 35-44.

[5] Najafzadeh, R., Abrishamchi, A., Tajrishi, M. and Shahr Ayini, H.T. (2005) Simulation of River Flow by a Snowmelt Model. Scientific Periodical of Water and Wastes, 52, 2-11.

[6] Tekeli, A.E., Akyurek, Z., Sorman, A., Sensoy, A. and Sorman, A.U. (2005) Using MODIS Snow Cover Maps in Modeling Snowmelt Runoff Process in the Eastern Part of Turkey. Remote Sensing of Environment, 97, 216-230. http://dx.doi.org/10.1016/j.rse.2005.03.013

[7] Lopez, P., Sirguey, P., Arnaud, Y., Pouyaud, B. and Chevallier, P. (2008) Snow Cover Monitoring in the Northern Patagonia Icefield Using MODIS Satellite Images (2000-2006). Global and Planetary Change, 61, 103-116. http://dx.doi.org/10.1016/j.gloplacha.2007.07.005

[8] Immerzeel, W.W., Droogers, P., De Jong, S.M. and Bierkens, M.F.P. (2009) Large-Scale Monitoring of Snow Cover and Runoff Simulation in Himalayan River Basins Using Remote Sensing. Remote sensing of Environment, 113, 40-49. http://dx.doi.org/10.1016/j.rse.2008.08.010

[9] Harshburger, B.J., Humes, K.S., Walden, V.P., Moore, B.C., Blandford, T.R. and Rango, A. (2010) Evaluation of Short-to-Medium Range Streamflow Forecasts Obtained Using an Enhanced Version of SRM1. JAWRA Journal of the American Water Resources Association, 46, 603-617.

[10] Regional Water Shares Company of Fars Province (2012) Project of Sheshpir Dam Reserve; First Phase of Study. Vol. 15, Abstract of Research Studies.

[11] Alavipanah, S.K. (2011) The Application of Remote Sensing in Earth Sciences (Soil Science). 3rd Edition, University of Tehran Publications Institute, Tehran.

[12] Sa'adat-Seresht, M. and Aziz-Mohammadi, M. (2005) A Review on Modern Concepts and Instruments for the Analysis and Interpretation of Remote Sensing Images. Collection of Articles on Workshops Concerning the Applicability of GIS and RS for Irrigation and Drainage Purposes, 3, 89-100. 